\title{
Cosplay Phenomenon: Archaic Forms and Updated Meanings
}

\author{
Tatiana V. Pushkareva ${ }^{1}$ \& Darya V. Agaltsova² \\ ${ }^{1}$ Candidate of Philosophy, Associate Professor of the Department of Design and Architecture \\ Synergy University, Moscow, Russia. ORCID: 0000-0002-9139-6121. E-mail: ap-bib@yandex.ru \\ ${ }^{2}$ Candidate of Pedagogy, Associate Professor of English Language Training and Professional \\ Communication Department, Financial University under the Government of the Russian \\ Federation, Moscow, Russia. ORCID: 0000-0001-8892-2437. E-mail: darya_agaltsova@mail.ru
}

\begin{abstract}
Cosplay is considered as a modern mass practice of copying and public demonstration of the costume, image and behavior of famous heroes in the mass culture: heroes of movies, cartoons, comics, video games within the framework of festivals, processions, activities of clubs of the corresponding subject. The empirical material for the study was observations, publications in specialized mass media, recordings of Russian and foreign electronic broadcasts of cosplay events, interviews with Russian cosplayers. The article provides a cultural and historical analysis of cosplay, on the basis of which it is concluded that the archaic cultural forms of totemic primitive holidays, medieval carnival, and the first forms of theater are reproduced in cosplay. Traditional cultural forms in cosplay are endowed with new cultural meanings, among which are the game principal development in culture, the implementation of special mechanisms of young people socialization through individual and collective forms of identification and imitation of famous characters, creative development of screen culture characters. In cosplay, there is a partial revitalization of archaic cultural forms, such as zoo-mystery, carnival, the first forms of theater. The conclusion is made about the role of cosplay in the development of the visual language of modernity, «de-virtualization» of the mass culture images and the development of the «instinct of theatricality» in a modern person. Cosplay in Russia demonstrates a wider thematic repertoire than cosplay in the USA and Japan: it includes not only images of American films, video games, comics, Japanese manga and anime, but also images of Soviet animation, which paradoxically are capable of direct competition with modern products of mass culture and art.
\end{abstract}

Keywords: archaic, cultural forms, cultural meanings, theater, youth, game industry, subculture, mass culture, cosplay, middle culture.

\section{Introduction}

The modern development of culture makes researchers increasingly talk about the crisis of cultural hierarchies, about the formation of a certain middle culture that removes the classical opposition of elite and mass culture (Tikhonova, 2017). Several factors influenced this change in the modern cultural landscape. First of all, this is the development of information technologies and the formation of a Web 2.0 system - a system that not only provides content to the consumer, but also assumes that a person can produce content and replicate it himself. Researchers say about the transition from a "culture of consumption" to a "culture of participation" (Malikova, 2015, 8). "Culture is, above all, free, active, and conscious participation of people in cultural and social 
processes, the ability for them to be not only "consumers" or the impact of objects, but to make its own contribution to the decision-making and the creation of cultural events" (Agapova, 2021, 10).

Another factor in the democratization and formation of middle culture was the growing visualization of culture, which is recognized in science as a pictorial turn (Mitchell, 1994). All this has led to the spread of new cultural practices, the theoretical understanding of which often lags behind. Paradoxically, it is the democratic style of modern culture that leads to the revitalization of archaic cultural forms and practices in new conditions. This new cultural practice has become the practice of cosplay.

Today, cosplay is called mass copying and public demonstration of the costume, image and behavior of famous heroes of mass culture: heroes of movies, cartoons, comics, video games within the framework of festivals, processions, and activities of clubs of the corresponding subject. Cosplay originated among fans of books, movies, then comics and video games. The initial desire of young people to imitate these heroes eventually turned into a special form of syncretic creativity, where a new or existing image is embodied by the participant with their own hands: from the costume, makeup to the logic and movement of the theatrical embodiment. The neologism "cosplay" comes from the Japanese abbreviation of the English phrase "costume play" - a costume game. In 2008, the word "cosplay" was included in the Oxford Dictionary.

Scientific understanding of the cosplay phenomenon has only just begun. So far, researchers have overwhelmingly phenomenally described the practice of cosplay, avoiding the essential, substantive definition. Samoylova E.O. defines cosplay as a game and the same time «near-game phenomenon» (Samoylova, 2016), unjustifiably in our view, «psychologizes» a theme requiring a systemic cultural-historical approach. The study of psychological aspects of cosplay was developed by Kulagina N. V., Ovchinnikova M. A. (Samoylova, Ovchinnikova, 2014). Penner R.V. considers cosplay as a psychological response to the anthropological crisis (Penner, 2016). Ryabinina A.M.'s extensive research on the development of semantics and connotations of the word «cosplay» in Russian mass media records: since 2015 the word «cosplay» itself becomes common and increasingly used as a concise metaphor («cosplay» - means to copy the costume and the behavior of a known character) already outside the context of its appearance and the epicenter of development (Ryabinina, 2018). On the whole, there is a consensus among Russian researchers that cosplay is a youth subculture, coming from the role-playing games subculture, but is increasingly going beyond it.

The purpose of the article is to analyze the cosplay practice in the context of the dialectic of form and meaning, showing how new meanings are placed and developed in traditional cultural forms that are actualized in the situation of "culture of participation".

\section{The origin of cosplay}

The earliest facts of the costumed materialization of mass culture characters in everyday human practice date back to the beginning of the XX century, when images from comics became popular at private costume parties in the United States. (Ryabinina, 2018). But the first experience of cosplay is considered to be the action of the science fiction writer Forest J. Ackerman, who, in 1939 at the first international science fiction festival "World Science Fiction Convention" - 
Worldcon, for advertising himself appeared in the image of his hero, quickly becoming a role model. In the 1960s, entire youth communities appeared, which made and tried on costumes and images of other science fiction characters.

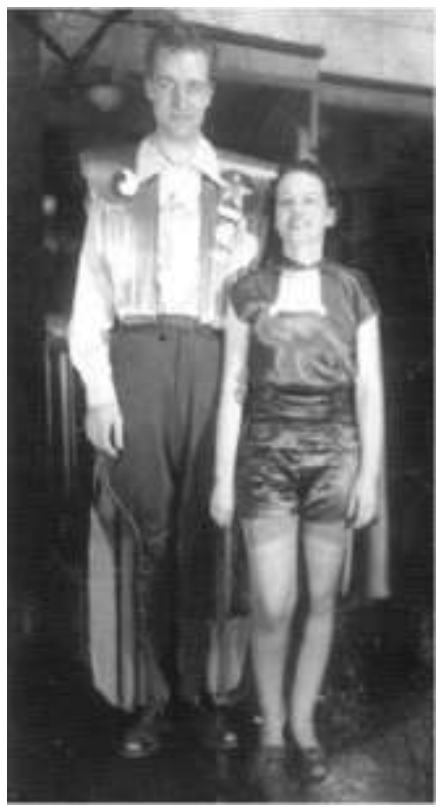

Figure 1. Figure 1. The first cosplayers. World Science Fiction Convention, 1939. CШA (https://www.syfy.com/syfywire/firsts-the-first-cosplay-took-place-at-the-first-ever-con-in-1939)

The institutionalization of cosplay was continued by several game festivals initiated in the 1970s and 1990s in the United States: the Comic-Con Games and entertainment Industry Festival, the AnimeExpo Japanese pop culture festival, and the A-Kon Anime festival. Now in the program of these festivals, along with music, dance, exhibitions, both a thematic masquerade and a cosplay contest are mandatory, where participants are required to have an original costume (65-75 percent) and also an author's representation of this costume, which becomes a kind of gold standard and a guarantee of quality.

The word "cosplay" was introduced by the Japanese journalist Nobuyuki Takahashi in 1983 (Takahashi, Yoshikoka, 1983) after visiting the Worldcon Science Fiction Festival in Los Angeles, the program of which by that time included not only discussions of literary, cinematic novelties, but also character costume contests. In the 2000s, cosplay festivals are becoming independent: an annual World Cosplay Summit was established in Nagoya, where the jury evaluated not only the costume, but also the action of the participant, and it had much more significance.

A great influence on the formation of cosplay was exerted by the Tolkienist subculture, which developed rapidly after the release and commercial success of the epic "The Lord of the Rings" in the United States by the English writer J. R. R. Tolkien (1892-1973). Since the 1960s of the XX century, Tolkienists were the first to conduct role-playing games in the field with elements of dressing up as heroes of the epic. Some of these stories later, in the 1970s of the XX century, have already passed into role-playing computer games. Such a circulation of popular stories between the real, book, and virtual world is still a characteristic of cosplay. For example, the plots of the book are developed in a video game, then materialize in the role-playing games of the 
same name, and then return to the screen in the cinematic variant. A vivid example of such circulation is the book "The Witcher Saga" by Andrzej Sapkowski, which became the basis for video games and role-playing games and, of course, cosplay images.

Cosplay, originally born in the United States, for a long time being developed as a subordinate element in various «fan» practices of science fiction fans, interpreters and fans of the genre of anime and computer games, has separated at the beginning of the third millennium, has spread to Europe and Asia and has become a worldwide cultural phenomenon.

\section{Proforms of cosplay}

One of the earliest cultural and historical prototypes of cosplay belongs to the primeval era. The study and reconstruction of the elements of the theater in the primitive era are possible thanks to the observations recorded by ethnographers, which were collected during expeditions to study societies at the stage of primitiveness, as well as thanks to the preserved primitive images. Based on these data, it was concluded that the first form of reincarnation of a person into another being was associated with a hunting disguise, a hunting rehearsal (Avdeev, 1959).

The symbolic reincarnation of a person into another being by dressing up took place during totemic zoophagical holidays ("zoomisteria"), these holidays marked the end of the hunting period, primitive people dancing symbolically reincarnated into their totemic ancestors, put on animal skins, animal heads, later masks and other attributes of a totemic animal or plant. The syncretism of zoophagical festivals and other primitive actions with elements of theater, such as the cult of ancestors, the funeral cult, determined the coordinates of the development of later cultural and historical forms (Semenov, 2002).

The researchers note that the special nature of performativity in the era of primitiveness is characterized here by two points: the absence of "spectacular consumption" and "mystical participation". The concept of "entertainment consumption" was formulated by the founder of the ethnographic theater in Russia, V. N. Vsevolodsky-Gerngross, it implies the division of those present into actors and spectators and is characteristic of classical theater and distinguishes it from ethnographic actions (Vsevolodsky-Gerngross, 1929). The concept of "mystical participation", used by L. Levi-Bruhl, characterizes the situation of complete identification of participants with the represented character (Levi-Bruhl, 2014). In cosplay, you can observe both moments. So, many cosplayers note the difficulty of separating their "I" from the character: after the game, the cosplayer has a kind of "train" from the character - a consequence of participation in his hero. The "spectacular consumption" of cosplay takes place in the format of a fashion show, in scenes with vocal, choreographic, sports numbers, and it is often assumed that a ramp or a podium is used. However, the audience in cosplay is often other cosplayers in the image of their characters, who during the event, in fact, just change places with the actors, so here we can talk about a situation of mutual "entertainment consumption". 
5 | Cosplay Phenomenon: Archaic Forms and Updated Meanings

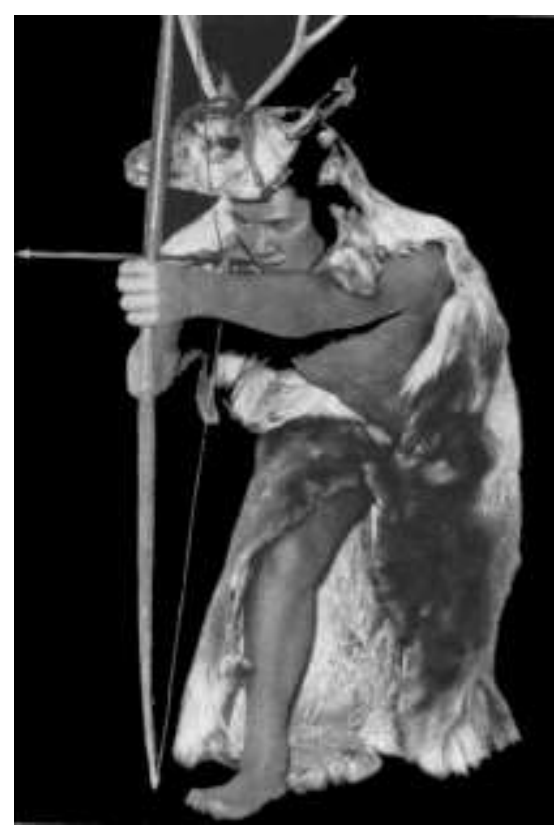

Figure 2. California Indian hunter (Avdeev, 1959, 47)

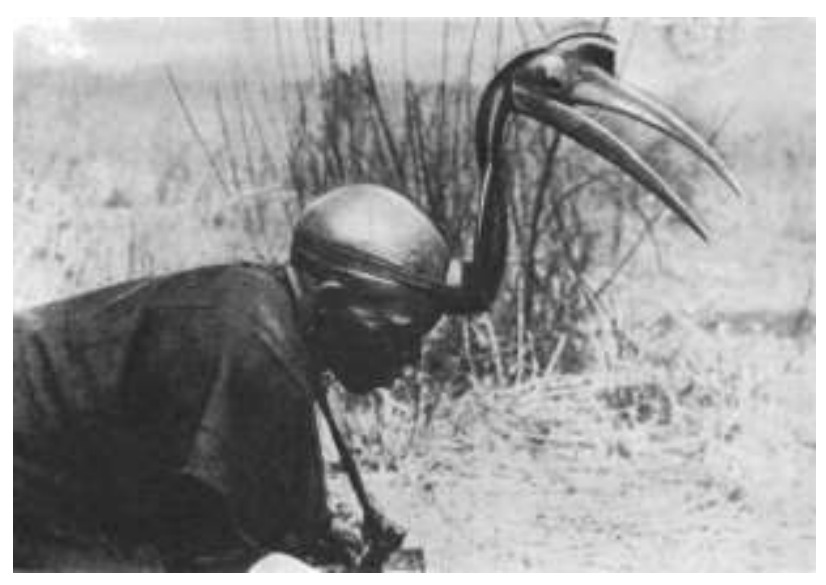

Figure 3. Hunting in Nigeria (Avdeev, 1959, 48)

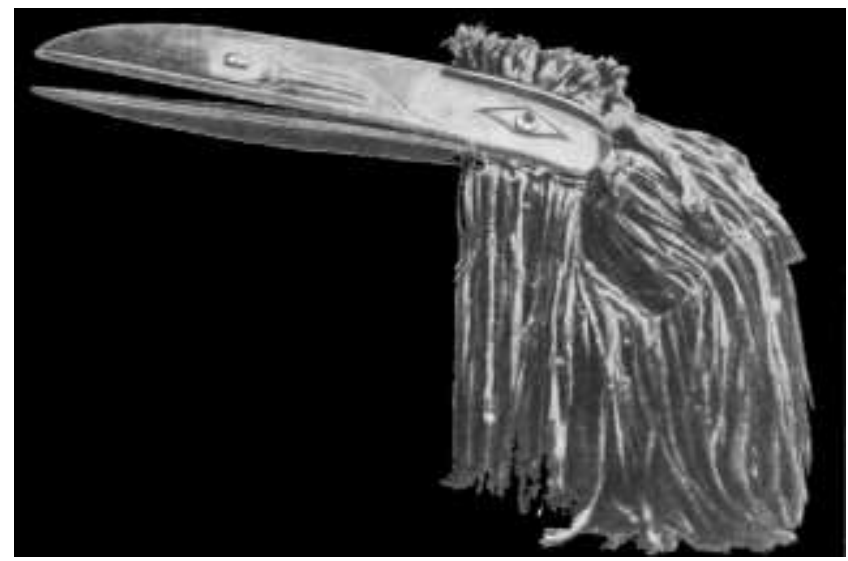

Figure 4. The mask and costume of the raven among the Kwakiuta Indians. (America) (Avdeev, 1959, 67) 
Cosplay simultaneously simulates the borderline situation of the interpenetration of the real and imaginary worlds, allows you to play with blurred boundaries between fiction and reality, which makes it similar to a medieval carnival. It is in the carnival in the history of culture that a radical transformation of everyday life takes place by changing clothes and changing the manner of behavior.

The cultural analysis of the carnival conducted by Mikhail Bakhtin in his "The work of Francois Rabelais and the folk culture of the Middle Ages and the Renaissance" shows how the archetypal "two-world" of human existence manifests itself in the carnival reality: "The real form of life is here at the same time its revived ideal form" (Bakhtin, 1965).

Carnival, which traces its history back to the Roman saturnalia, holidays during which social differences between citizens and slaves were abolished, thereby there was a short return to the "golden age", the age of primitive equality. The carnival reproduces not only the situation of equality in the human collective, but also the situation of unity of the human collective with nature and the world. The "reborn ideal form of life" in the carnival, about which Bakhtin writes, temporarily removes, thus, the double alienation of man: "Man was reborn, as it were, for new, purely human relations. The alienation temporarily disappeared. A person returned to himself and felt like a person among people. And this genuine humanity of relations was not only an object of imagination or abstract thought, but was actually realized and experienced in a living materialsensory contact. The ideal-utopian and the real temporarily merged in this unique carnival worldview" (Bakhtin, 1965). That is why, according to Bakhtin, "the national festive carnival beginning is, in fact, indestructible. Narrowed and weakened, it still continues to fertilize various areas of life and culture" [Bakhtin, 1965, 51], and cosplay has probably become just such an area.

The demonstration of cosplay images usually includes "acting out" - copying the character's behavior in micro-movements or in an expanded theatrical form. Cosplay scenes last several minutes or more, are often directed, include dance, pantomime, vocals, sports numbers, are presented to music, but completely exclude the word. This already fully theatrical practice refers us to the traditions of ancient Greek mimes (from Greek. mimos-imitation), as well as at the dawn of the history of the theater, it has a competitive character, and the jury at cosplay events evaluates both the costume and the action.

\section{New socialization}

The first American cosplayers were schoolchildren who are too diligent in their studies, do not know how to have fun and often have difficulties communicating with their peers. For such young people, cosplay is still becoming one of the ways to restore the integrity of the experience of being. There are still several studies, according to which young people who have problems with socialization are involved in the practice of cosplay. Cosplay events become a kind of recreation, where there is a temporary departure from the existing social hierarchies. This has its dangers: it is also possible to refuse to solve the real problems of your life, limiting the scope of your activity to hobbies, this escapism is the reverse side of modern carnival practices.

The flash mob "Izoizolatsiya" in the Russian-speaking segment of the Facebook network, which unfolded during the quarantine in the spring of 2020, became a kind of variation of cosplay. 
People who are in self-isolation created compositions using improvised materials that copy famous paintings and sculptures (Reznik, 2020).

The characters chosen by the participants of the cosplay events for their miniperformances (except for the genre of the original version) are well known to the audience and other participants. Most of the images chosen for cosplay are connected to American and Japanese popular culture: this is the heroine of the Disney cartoon "Alice in Wonderland", the heroes of the manga (Japanese visual novel, or comic book) and anime (Japanese animation), Queen Otohime, Rosen Maiden dolls, Naruto, Lord Shen from the computer animated series "Kung Fu Panda", the heroes of the movie "Avatar", the Pokemon franchise, the heroes of the English video game "Warhammer 40,000" (based on the board game), a Japanese video game "Mario". Although now there are quite a lot of examples of cosplay heroes of works and national cultures. For example, in Russia there is a practice of cosplay heroes of Soviet animation.

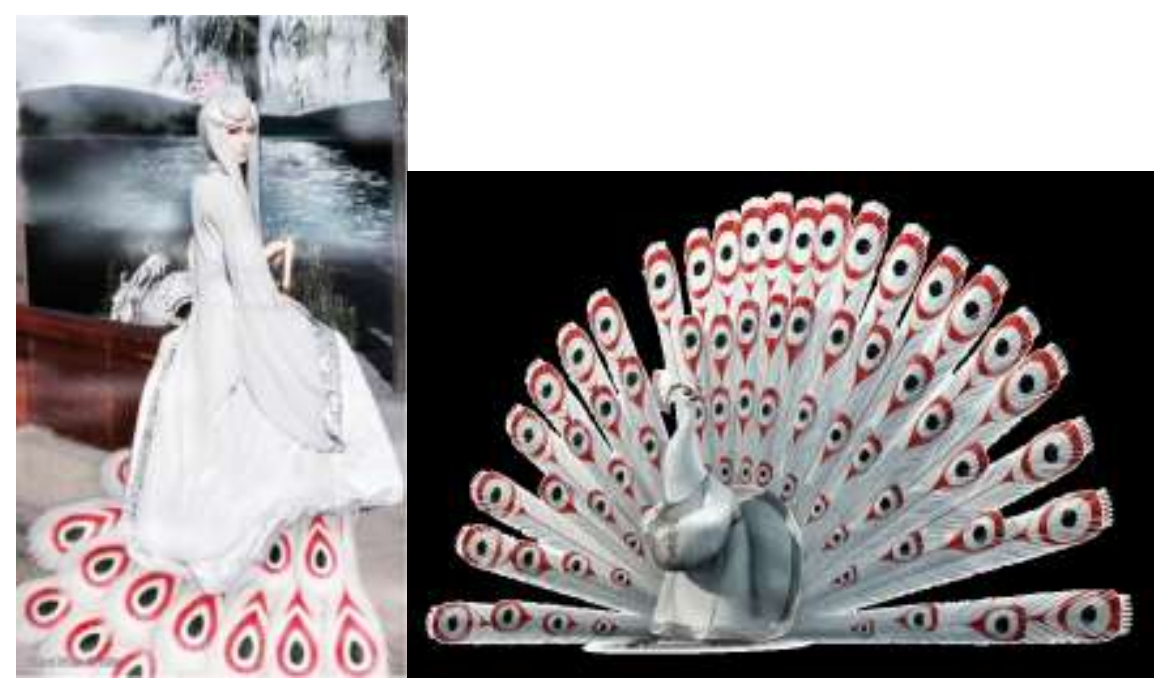

Figure 5. Cosplay image of Lord Shen from the cartoon "Kung Fu Panda 2" (USA, 2011). (https://otvetus.com/kto-vash-lyubimiy-zlodey-vseh-vremen-95544)

The socio-psychological mechanisms that underlie the practice of cosplay are imitation and identification, and they are common to cosplay theater. The practice of cosplay allows you to become someone else not only in the imagination, but also partly in the objective world. Cosplay has a socializing effect: playing a role, you can learn to better understand others. The cosplayer constructs his persona, mastering new images, thus studying his subpersonalities. The cosplayer chooses each image independently and individually, and making this choice, each time he tries to understand himself and look at himself from the outside.

Here is how one of the participants of this practice (Moscow, a girl, 21 years old) explains the psychological mechanism of cosplay, an interview with which became one of the empirical sources of the article.

"Trying to" stay " in the personality of the chosen character allows the cosplayer to behave differently than in ordinary life. A shy person, fascinated by the daring Naruto (a character in the anime Naruto of the same name), has the opportunity to try a different model of behavior. The 
stories of the characters play an important role in the formation of this self-identification. Heroes and villains help us learn about different ways to solve problems that arise in life. By experiencing their self-image, we have the opportunity to look at life through their eyes. That is why all the details of the costume should be as close as possible to the screen or the graphic aspect of the idol. We are not afraid to look strange or even a little scary. Most cosplayers don't feel like monsters or so - called "geeks" - fans, we seriously think that we are forming a new culture in our own way. For cosplayers, it is important to feel a connection with the character. Through cosplay, they show that they share his ideas and principles, as if they are telling others that they want to be like their favorite hero. People tend to choose role models - cosplayers do it more explicitly. Many cosplayers began to invent their own image, rather than using ready-made canons. There are no special canons for original cosplay, but there are some rules, the main one of which is the presence of an idea. Wearing wig and beautiful clothes is not enough. The idea is important for the original image. These ideas can be the representation of a book or a myth, the personification of a hero, the personification of the weather, the month, an animal, changing the sex of an existing character, etc. It is important that the image is detailed, interesting and «alive». When creating a costume, cosplayers are involved in a time-consuming and lengthy process. Despite the fact that it is often possible to simply buy the costume of your hero ready-made, such a choice does not always correspond to the desired result, so even the purchased costume adapts to the order or production independently. In the process of preparing the image, the cosplayer has to pay for everything independently, so high-quality cosplay is quite expensive, it often becomes an incentive for earning money. In general, cosplay is an activity for hardworking, patient people with a good imagination. A suit for this direction is considered by them as a good way to avoid the daily routine».

The task of the cosplayer is not to introduce the audience to the work and the hero but to materialize a familiar image and express the essence of the character with minimal theatrical means. The participant of the cosplay event and the recipient of the cosplayer's work (including the jury) is interested in how accurately and how the costume is made, what props are selected, how accurately a well-recognized image is transmitted, how it enters into non-verbal communication with the audience. The cosplayer performs in many faces at once: as a designer and creator of a costume, as a director and an actor who represents an image. Choosing famous characters for his visualization, the cosplayer, on the one hand, automatically joins his success and popularity, thus minimizing creative risks, on the other hand, develops a syncretic egovisualization of the image, different from both archaic practices and traditional theatrical forms.

\section{Cosplay in Russia}

The first cosplayers in Russia appeared in 1999, this is the time when the "Iron Curtain" begins to collapse, and at the same time, cosplay becomes a worldwide phenomenon, revealing both universal and regional features. American cosplay turned out to be traditionally associated with science fiction festivals, with the video game industry and the rapidly spreading fashion for comics, and then for manga and anime in the country. In Japan, cosplay, partly referring to the traditions of the national Kabuki theater with its attention to facial expressions and gesture, has a generally chamber character and develops manga and anime plots. The practice of cosplayers is developing in the formats of cosplay bars, photo shoots, clubs, and at the same time, Japan is becoming the 
center of world cosplay thanks to the largest Tokyo Game Show festival and the World Cosplay Summit (WCS), which has been held since 2012.

In Russia, cosplay events are now held in more than 50 Russian cities, and the cosplayers themselves are a youth subculture, the average age of its representatives is 12-25 years. However, this subculture often acquires an intergenerational character both within the same family and outside it (Kulagina, Ovshinnikova, 2014).

During the short time of the existence of cosplay as a part of the gaming industry and mass culture form, certain types (or genres) with their universal and national features have emerged. Previously, the following genres can be distinguished: standard cosplay; transformation with entourage; photo cosplay; craft; original version; body art cosplay; video cosplay; fursyu; chibi-cosplay; humanization (representation of an animal or object in the form of a person); cosplay for a fan service; cosplay subculture. It is interesting that in the genres of cosplay there is also an original genre, in which it is assumed not to copy, but to create your own image.

In general, the theme of anime-cosplay has received rapid development in Russia, especially in the regions of Russia that are geographically close to Japan and Korea. Among the Russian cosplay festivals can be called Animatsuri, Tanibata. Otakun, ANI. MA. U, Mikan no yuiki, Siberia Otaku Saiten, Dai-fest. The following thematic magazines are published - "AnimeMag", "AnimeGid", "ProCosplay", "The World of Anime", "RuManga", there are specialized stores "Animefan.ru", "AnimePoint", "FastAnime". The fascination with anime in Russia led to the creation of a subculture that includes language, behaviors, customs, and cosplay also became part of this subculture, physically visualizing the planar image of anime.
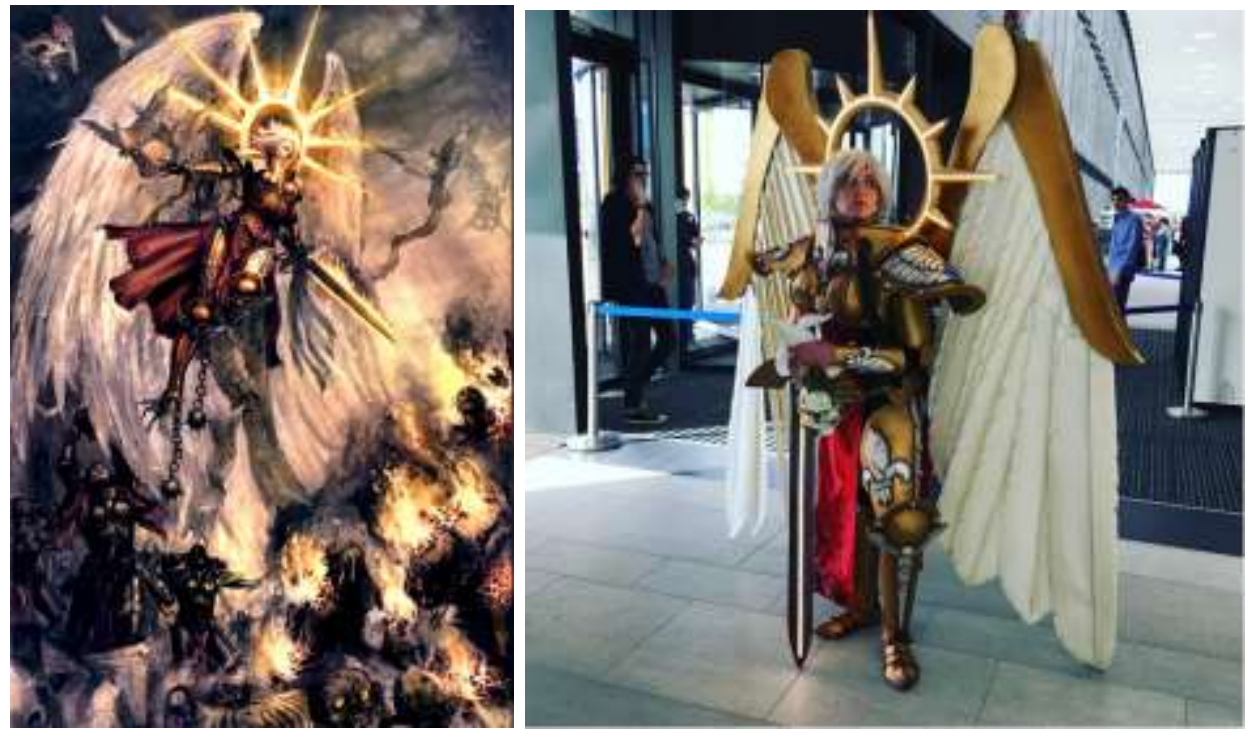

Figure 6. The cosplay image of Saint Celestine from the video game "Warhammer 40,000".

Polina Vishnevskaya (Ufa). (https://ucrazy.ru/foto/1532666609-snogsshibatelnyy-kospley-svyatoycelestiny-iz-warhammer-40000.html ) 

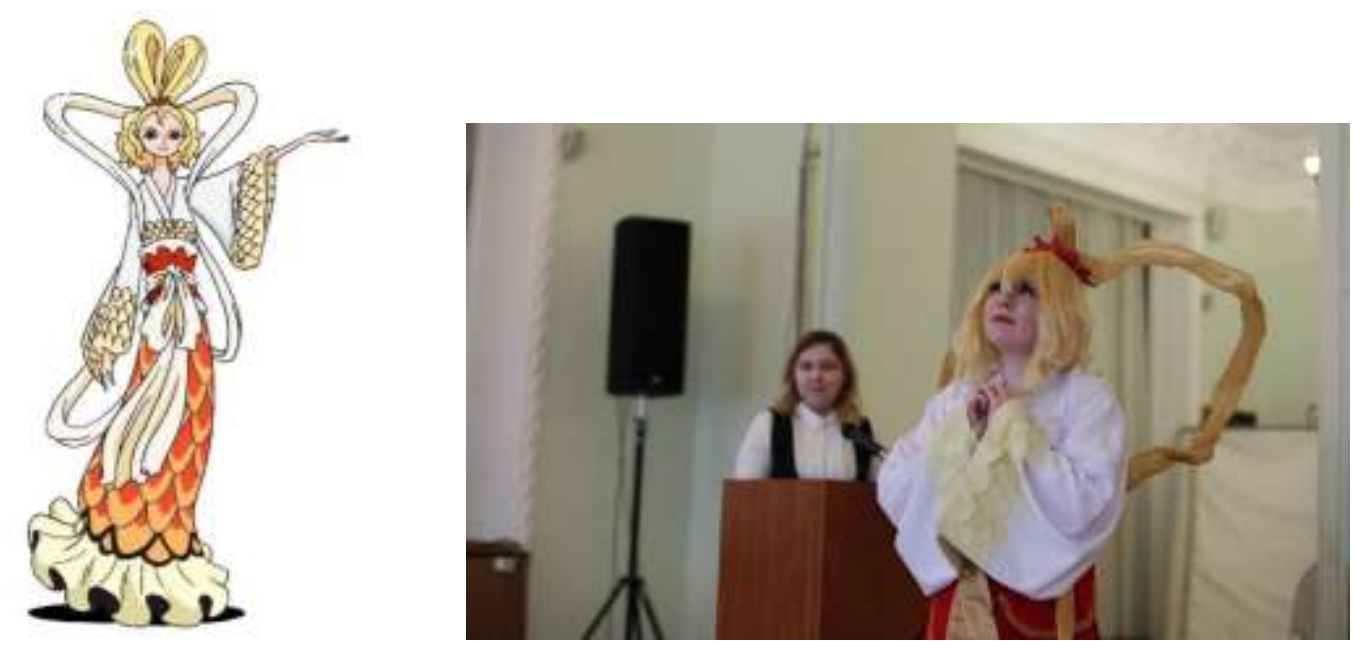

Figure 7. Cosplay image of Queen Otohime from the anime "One Piece". Cosplayer Ulyana Murzina demonstrates the costume of the heroine of a Japanese animated film, speaking at a conference at the Russian State Social University.

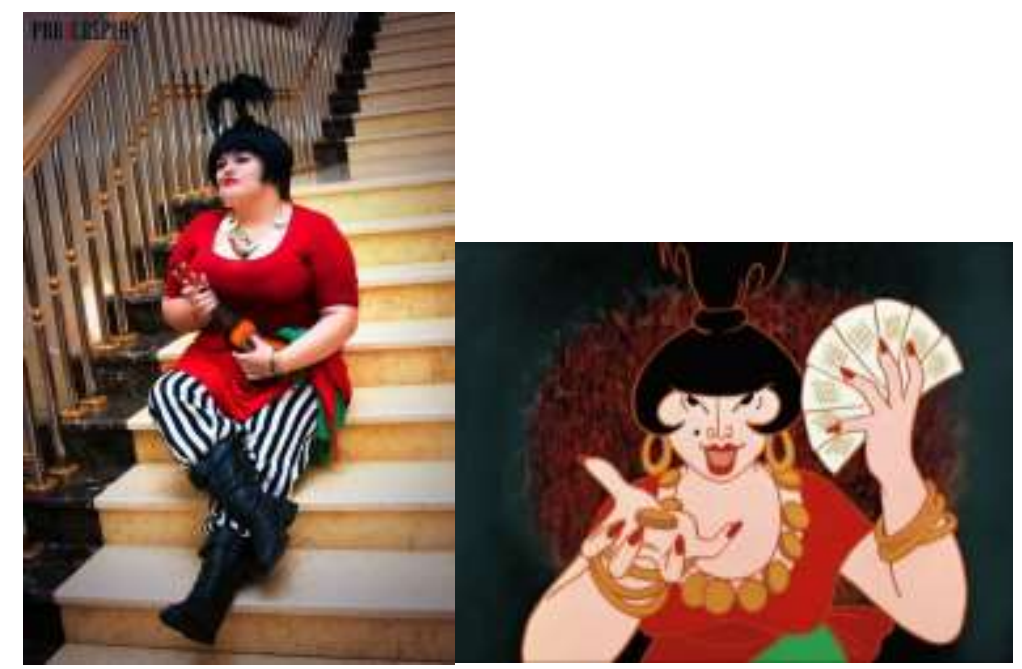

Figure 8. Cosplay image of the chieftain from the cartoon "The Bremen Town Musicians" (USSR, 1969) (https://www.deviantart.com/matsu-sotome/gallery/54889909/russian-fendoms) 


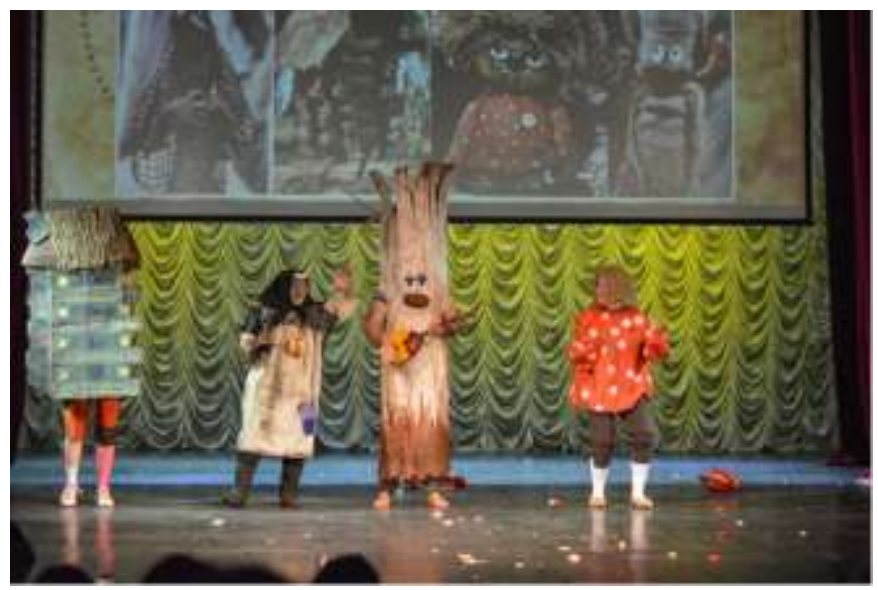

Figure 9. Cosplay image of the chieftain from the cartoon "Domovenok Kuzya " (USSR, 1984)

The peculiarity of Russian cosplay is that, in comparison with the American and Japanese versions, it has a wider thematic repertoire: along with the plots and heroes of American films, games, comics, heroes and themes of Japanese manga and anime, Russian cosplay develops an original direction associated with the visual development of the figurative system of Soviet animation of the 1960s-1980s, when it experienced an unprecedented flourishing, leaving works of world artistic level.

It is also interesting that Soviet animation has the opposite effect on Japanese animation: the hero Cheburashka from the cartoon "Crocodile Gena" (1969) inspired the Japanese director Makoto Namakura, who created a kind of continuation of the Soviet cartoon in 2010 and made Cheburashka famous in Japan.

Also, the specifics of Russian cosplay can be considered a special attention to "acting out" when creating the image of a character, that is, building the behavior of the hero, which may be associated with the theatrical traditions of Russian culture.

\section{Conclusion}

The phenomenon of cosplay as one of the directions of mild-culture and "culture of participation" is a mass practice of copying and public demonstration of the costume, image, and behavior of famous heroes of mass culture: heroes of movies, cartoons, comics, video games within the framework of festivals, processions, activities of clubs of the corresponding subject. In cosplay, there is a partial revitalization of archaic cultural forms, such as zoo-mystery, carnival, the first forms of theater. Through the syncretic ego-visualization of images in mass culture, selfknowledge and socialization of a young person is carried out, there is a "de-virtualization" of the mass culture images and the development of the visual language of modernity. The development of cosplay in Russia demonstrates a wider thematic repertoire, including not only images of American films, video games, comics, Japanese manga and anime, but also images of Soviet animation, which, thus, are capable of direct competition with modern products of mass culture. 


\section{Funding Disclosure/Acknowledgement}

The article is a part of the Society of Professional Sociologists' research programs, supported by the Russian Fund for Basic Research. Research project RFBR № 19-011-00943 "Forward to the past: archaism and archaization trends in contemporary Russian society (interdisciplinary analysis)" (2019-2021).

\section{References}

Agapova, D. (2012). Culture of participation: millions of dialogues. In Shcherbakova, A. The museum as a space of education: play, dialogue, culture of participation. Moscow. P. 8-21.

A-Kon. URL: https://www.a-kon.com (accessed: 6.07.2021)

AnimeExpo. URL: https://www.anime-expo.org/explore/events (accessed: 6.07.2021)

Bakhtin, M. M. (1965). The work of Francois Rabelais and the folk culture of the Middle Ages and the Renaissance. Moscow. 543 p.

Comic-Con. URL: https://comic-con.org (accessed: 6.07.2021)

Kulagina, N.V., Ovchinnikova, M.A. (2014). Motivation of cosplay players with different experience of participation in a role-playing game. Concept 5. URL: http://e-koncept.ru/2014/14115.htm (accessed: 6.07.2021)

Levi-Bruhl, K. (2014). Primitive thinking. Moscow, 2014

Malikova, D. N. (2015). Methods of working with the art museum audience: from traditional educational practices to mediation (Understanding and integrating the experience of the European Biennale of Contemporary Art "Manifesta 10"). Yekaterinburg, $116 \mathrm{p}$.

Mitchell, W. J. T. (1994). The Pictorial Turn. Picture Theory. Essays on Verbal and Visual Representation. Chicago, London: The University of Chicago Press. P. 11-34.

Penner, R. V. (2016). De are ad absurdum: the problem of human identity in the phenomenon of cosplay (ontoanthropological analysis)). Society and power. 3. pp. 117-122.

Reznik, N. (2020). "Izoizolyatsiya": from home theater to a public event. URL:

https://www.colta.ru/articles/art/24459-izoizolyatsiya-ot-piktorializma-k-obschestvennomu-sobytiyu (accessed: 6.07.2021).

Ryabinina, A.M. (2018). "Otaku is being attacked": the Russian cosplay community in media publications (based on articles from 1999-2017). Article. 29.

Samoylova, E. O. (2016). "Near-game phenomena" and imperatives of the modern consumer society. Historical, philosophical, political and legal sciences, cultural studies and art criticism. Questions of theory and practice. Tambov: Diploma. 12(74), 2. C. 142-145.

Samoylova, E. O. (2014). Ontological components of the cosplay phenomenon. Basic research. 9 (3). pp. 678-681. URL: https://fundamental-research.ru/ru/article/view?id=34911 (date of reference: 6.07.2021)

Semenov, Yu. I. (2002). How humanity arose. Moscow. 790p.

Tikhonova, V. L. (2017). Mass culture and the problem of its influence on the consciousness of recipients. Historical, philosophical, political and legal sciences, cultural studies and art criticism. Questions of theory and practice. Tambov: Diploma. 11(85) P. 171-173. 
13| Cosplay Phenomenon: Archaic Forms and Updated Meanings

Takahashi, N., Yoshikoka H. (1983). Costume Play. My Anime. 6. P. 107-110.

Telegina, M. S., Astafyeva, T. V. (2019). Formation and development of cosplay festivals in the USA, Japan and Russia. Bulletin of KemGUKI. 48. pp. 85-90.

Vsevolodsky-Gerngross, V. N. (1929). History of the Russian Theater. Vol. 1, 2. Moscow, Leningrad. 1929.

Woldcon. URL: http://www.worldcon.org (accessed: 6.07.2021)

World Cosplay Summit. URL: https://www.youtube.com/channel/UC5VBrQEonivcMLx8krq-CwQ (accessed: 6.07.2021)

Oxford Dictionary includes the words "cosplay" and" botnet" URL: https://lenta.ru/news/2008/07/03/words (accessed: 6.07.2021)

Tatiana V. Pushkareva, Candidate of Philosophy, Associate Professor of the Department of Design and Architecture Synergy University Russia, Moscow. In 1994 graduated from the Historical Faculty of the Moscow State Pedagogical University. In 2001 defended the Candidate dissertation on the topic of «History-culture-memory: concerning the problem of historical time». Research internships at the universities in Germany and Spain. In 1999 to 2020 worked in Russian State Social University. Research interests: memory studies, modern culture, modern society, temporality, visual culture. Author of more than 100 scientific works.

Darya V. Agaltsova, Candidate of Pedagogy, Associate Professor of English Language Training and Professional Communication Department, Financial University, Moscow, Russia. In 2002 graduated from the Computer Science Faculty of Omsk State Pedagogical University (Specialty: Teacher of Computer science and English language). Since 2019 works at the Financial University under the Government of the Russian Federation. Research interests: new information technologies in education, modern society, English as a foreign language. Author of more than 30 scientific works. 